\section{Effect of bromocriptine on plasma growth hormone and glucose tolerance in chronic renal failure}

Chronic renal failure is associated with high circulating levels of growth hormone $(\mathrm{GH})$ which are not affected by stimuli such as glucose loading. ${ }^{1}$ They may be due to delayed degradation, excessive secretion, or both. Secretion of GH seems to be increased by catecholamines. ${ }^{2}$ Bromocriptine (2-brom-alpha-ergocryptine; CB 154), an ergot alkaloid with dopaminergic activity, suppresses abnormal GH secretion in patients with acromegaly ${ }^{3}$ but not in normal subjects or in patients with diabetes mellitus. ${ }^{4}$ We therefore assessed the effects of bromocriptine on abnormal GH secretion in response to glucose loading in patients with chronic renal failure.

\section{Patients, methods, and results}

Four well-nourished patients treated with chronic intermittent haemodialysis ( $18 \mathrm{~h} /$ week, Kiil multipoint) were studied. After an overnight fast and with the patient resting in bed an intravenous glucose tolerance test was done about 14 hours after the previous haemodialysis. Venous samples were collected with an indwelling catheter. After a fasting specimen of blood had been obtained $140 \mathrm{mmol}$ glucose (as a $2.78 \mathrm{mmol} / 1$ aqueous solution) was given intravenously over two minutes into the opposite arm. Thereafter samples were withdrawn $3,6,10,15,30$, and 60 minutes after the start of the infusion.

The patients were then given bromocriptine $2.5 \mathrm{mg}$ daily with food. The dose was increased by $2.5 \mathrm{mg}$ every second day until the daily dose was $10 \mathrm{mg}$ ( $2.5 \mathrm{mg} 6$-hourly). When this dose had been taken for two days a second intravenous glucose tolerance test was performed at a similar time relative to dialysis.

Plasma GH and insulin were estimated by radioimmunoassay, and blood glucose by a glucose oxidase method.

One patient had persistent hypotension when taking the full dose of bromocriptine $(10 \mathrm{mg} /$ day $)$. A fasting sample of blood was taken but a second glucose tolerance test was not done. Another patient noted transient nausea and hypotension. Before treatment glucose tolerance was normal $(k=2.87 \% / \mathrm{min})$. Fasting levels of $\mathrm{GH}$ were raised in 3 of the 4 patients (mean ( \pm SEM) $3.8 \pm 1.4 \mu \mathrm{g} / \mathrm{l}$ ) and in all patients paradoxical rises of $\mathrm{GH}$ were seen (fig).
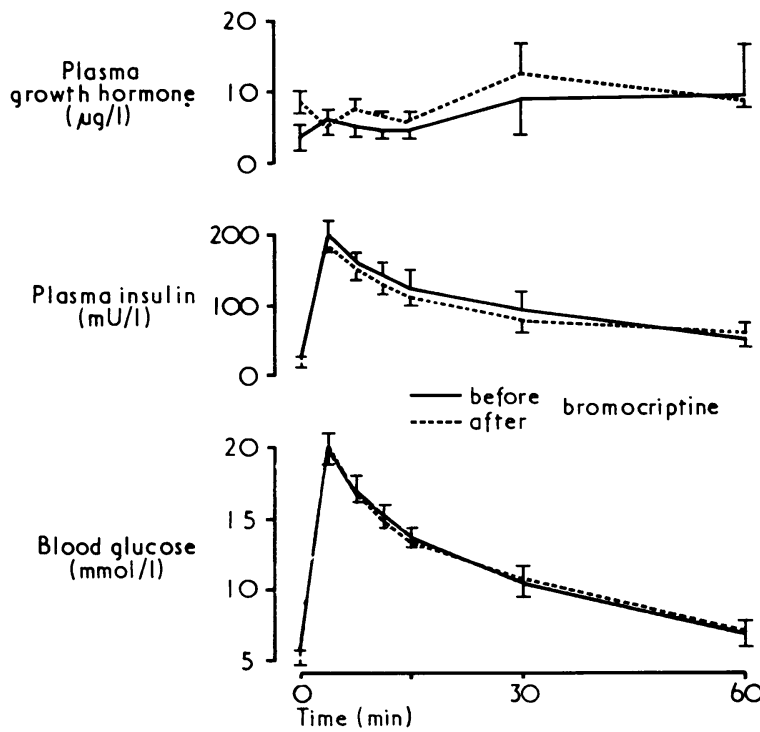

Mean $( \pm S E M)$ responses of blood glucose, plasma insulin, and growth hormone to intravenous glucose in dialysed patients with chronic renal failure before and after treatment with bromocriptine.

Treatment with bromocriptine did not affect glucose tolerance or insulin response. Fasting levels of $\mathrm{GH}$ were consistently higher after treatment (mean $8.5 \pm 1.5 \mu \mathrm{g} / \mathrm{l})$ than before treatment $(\mathrm{P}<0.01)$. The nature of the $\mathrm{GH}$ response to glucose remained abnormal after treatment.

\section{Discussion}

In contrast to its effect in acromegaly, ${ }^{3}$ treatment with bromocriptine $10 \mathrm{mg} /$ day in patients with renal failure neither suppressed the fasting levels of $\mathrm{GH}$ nor altered paradoxical secretion of $\mathrm{GH}$ after administration of glucose. This suggests that dopaminergic receptors in the hypothalmic region of patients with chronic renal failure function normally and that the paradoxical secretion of $\mathrm{GH}$ after the administration of glucose is mediated by mechanisms which differ from those in acromegaly.

Despite the rise of fasting levels of $\mathrm{GH}$ no changes were noted in glucose tolerance or insulin response. Therefore $\mathrm{GH}$ levels are probably not a major factor in the abnormal carbohydrate tolerance of chronic renal failure.

We thank Dr G R Kennedy, Sandoz Ltd, for supplying the bromocriptine and for financial assistance.

1 Samaan, N A, and Freeman, R M, Metabolism, 1970, 19, 102.
2 Martin, J B, New England fournal of Medicine, 1973, 288, 1384.
3 Thorner, M O, et al, British Medical fournal, 1975, 1, 299.

${ }^{4}$ Cassar, J, et al, Lancet, 1975, 2, 181.

Renal Unit, Churchill Hospital, Oxford OX3 7LJ

J A KANIS, BSC, MRCP, MRC, clinical research fellow

J G G I.EDINGHAM, DM, FRCP, May reader in medicine

D OLIVER, MB, FRCP, consultant physician

R J WALTON, BSC, MRCP, Goodger scholar

Metabolic Unit, Western General Hospital, Edinburgh EH4 2XU I M NAIRN, BSC, senior biochemist

\section{Hazards of monocomponent insulins}

Conventional insulins are being replaced by the new monocomponent insulins (Actrapid MC, Semitard, and Monotard), which are claimed to be more beneficial. ${ }^{1}$ The following report, however, shows that dosage requirements in individual patients may be much smaller than with standard insulins, and thus more warning of the changeover should be given.

\section{Case report}

A 15-year-old boy who had been diabetic for three years was stabilised initially on twice daily soluble insulin with transfer for a few months to insulin lente once daily. The only complication of his diabetes had been severe renal glycosuria, though in April 1974 he had had an episode of diabetic ketoacidosis caused by a dental abscess. His insulin requirements, always rather high, then began to increase, and by November he was taking up to 280 units of ordinary (beef) soluble insulin daily. He was admitted to hospital for transfer to neutral soluble insulin (Actrapid). Initially his insulin requirement fell by $23 \%$ (see fig) but it rapidly rose again, and by May 1975

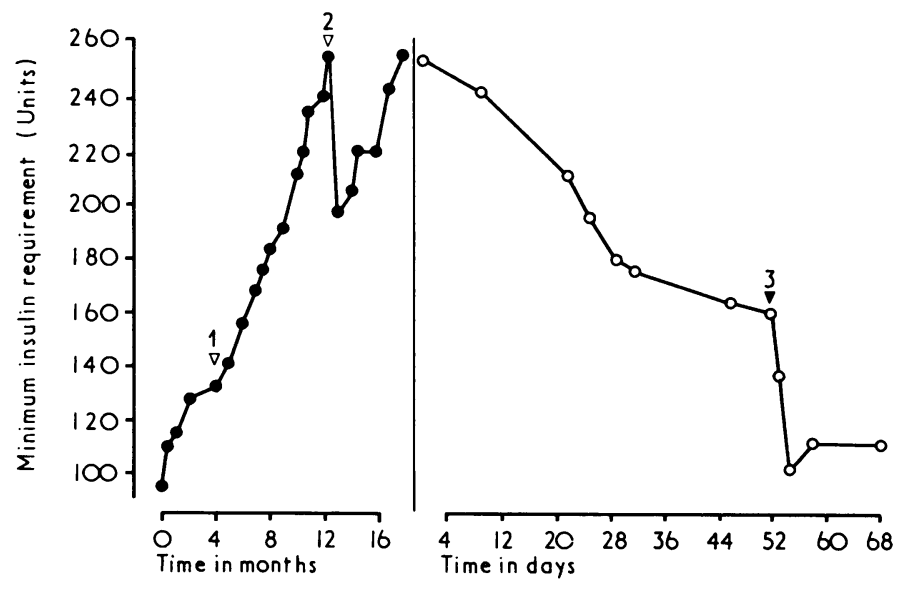

Sequential change in minimum insulin requirement. $1=$ Episode of ketoacidosis. $2=$ Change to neutral soluble (pork) insulin (Actrapid). $3=$ Change to monocomponent insulin (Actrapid MC). 
he was taking a minimum of 256 units daily. Thereafter the dosage dropped progressively, but seven weeks later he still needed up to 188 units daily. He was then transferred to Actrapid MC. In three days his insulin requirement fell by $36 \%$ to 102 units daily. He was stabilised on twice daily Actrapid MC in a total dose of 112-124 units daily and remained well controlled, with a mean mid-morning blood sugar level of $6.1 \mathrm{mmol} / 1(110 \mathrm{mg} / 100 \mathrm{ml})$. His daily diet $(9 \cdot 2 \mathrm{MJ} ; 2200 \mathrm{kcal})$ and weight remained unchanged. At the time of maximum insulin resistance there was no evidence of severe infection any other precipitating factor; in particular, his growth hormone levels were normal.

\section{Discussion}

Although claims that monocomponent insulins are highly purified and virtually non-antigenic ${ }^{2-4}$ have been challenged, ${ }^{5}$ they may be of benefit to patients with insulin resistance ${ }^{1}$ and allergies and in atrophic and hypertrophic types of lipodystrophy. Their use in newly diagnosed diabetics might help to avert complications due to the formation of insulin antibodies, although the significance of this is still under debate. ${ }^{2}$ A potential disadvantage is that they may have a shorter duration of action than conventional insulins because binding insulin to the tissues.

Our patient was clearly coming out of his insulin-resistant phase before changing to monocomponent insulin, but his immediate fall of $36^{\circ}$ in insulin requirements on transfer to Actrapid MC could have had serious consequences had the changeover been attempted outside hospital. This fall was probably more drastic than average, but the overall frequency of decreased requirements compared with less pure insulins has been reported to occur in some two out of three such transfers. The packaging of the new monocomponent insulins is closely similar to that of the standard insulins marketed by the manufacturer (Novo Industri), and we are concerned that patients already taking the latter may unwittingly be supplied with monocomponent insulins as a renewal of prescription and may therefore be at risk of severe hypoglycaemic reactions. We therefore suggest that patients changing to monocomponent insulins from beef insulins should make a $20 \%$ cut in dosage, and those changing from monospecies pork insulins, which are less antigenic, a $15^{\circ}$ reduction initially, and that finer adjustments should be made thereafter under close supervision.

${ }^{1}$ Korp, W, and Levitt, R E, Wiener klinische Wochenschrift, 1973, 85, 326.

${ }^{2}$ Andreani, D, et al, Hormone and Metabolic Research, 1974, 6, 447.

${ }^{4}$ Czyzyk, A, et al, Diabetologia, 1974, 10, 233.

5 Yue, D K, and Turtle, J R, Diabetes, 1975, 24, 625.

Diabetic Clinic, Aberdeen Royal Infirmary, Aberdeen AB9 1 GS

A W LOGIE, MB, MRCP, senior medical registrar

J M STOWERS, MD, FRCP, consultant physician to circulating antibody is thought to delay availability of active free

3 Schlichtkrull, J, et al Diabetes, 1972, 21, suppl 2, p 649.

$200 \mathrm{mg}$ for louse-borne typhus fever ${ }^{2}$ and tick-borne relapsing fever, ${ }^{3}$ $300 \mathrm{mg}$ for uncomplicated gonorrhoea, ${ }^{4}$ and $500 \mathrm{mg}$ for uncomplicated lobar pneumonia (unpublished, Pfizer Ltd), have been reported. We therefore measured serum levels after a single dose of $500 \mathrm{mg}$ in healthy adults to establish a rationale for this dose level.

\section{Methods and results}

Fourteen female and six male healthy, adult Nigerians between 20 and 45 years of age volunteered for the study. After a zero blood sample taken after breakfast, five doxycycline hyclate capsules $(500 \mathrm{mg}$ ) were given orally with a glass of water over 5-10 minutes. Serial blood samples were then taken initially from nine volunteers up to 48 hours and subsequently from 11 volunteers up to 120 hours and from three up to 144 hours. Light refreshments were served during the first few hours and the subjects then returned home to their routine lives, reporting on subsequent days for blood sampling after breakfast. The serum concentration of doxycycline was determined by the fluorometric method of Kohn, ${ }^{5}$ using a Farrand Model A fluorometer.

The results are summarised in the table. Two subjects, who vomited during the second hour after taking the capsules, had peak serum concentrations of 11.30 and $8.00 \mathrm{mg} / \mathrm{l}$. Two other subjects complained of abdominal rumblings on the first evening of the study. Using an aqueous solution of doxycycline in three experiments, and doxycycline powder in two, mean percentage recoveries of doxycycline from whole blood in vitro were $37 \%$ and $24 \%$ respectively. A further extraction of the haemolysed red cell "debris" gave a mean percentage recovery of $55 \%$, which gave a total recovery of $92 \%$ and $79 \%$ with the aqueous solution and the powder respectively.

\section{Discussion}

Doxycycline was rapidly absorbed by all subjects, with peak serum levels after four hours. The mean peak level of $15.29 \mathrm{mg} / 1$ is much higher than those reported for lower doses, ${ }^{1}$ but the fluorometric measurement of doxycycline gives higher values than the microbiological assay. The in-vitro experiments suggest that serum doxycycline represents only a fraction of the level in blood. The association of a larger percentage with the red cell "debris" suggests that serum doxycycline binds to these cells. While the significance of this cannot be fully inferred now, it indicates that much higher levels are present in whole blood than in serum.

The fact that the generally accepted clinically effective serum level of $1 \mathrm{mg} / \mathrm{l}$ was maintained for up to four days with a single $500-\mathrm{mg}$ dose of doxycycline establishes a rationale for clinical trials of singledose therapy. This could be particularly useful in åreas of the world where patients missing doses, or taking too many capsules, present as problems in the prescription of antibiotics in outpatient and general practice clinics. Its proved efficacy may also be of advantage in dealing with acute illnesses of bacterial origin where facilities do not permit close and frequent supervision of patients by a medical team.

We are grateful to Pfizer Products Ltd, Ikeja, Nigeria, and Pfizer Corporation, Nairobi, Kenya, for their support and the supply of doxycycline.

\footnotetext{
1 Wittenau, M Schach von, in Opuscula Medica 1974, suppl 35, p 5

${ }^{2}$ Huys, J, et al, Chemotherapy, 1973, 18, 314.

${ }^{3}$ Clercq, A G de, et al, East African Medical fournal, 1975, 8, 428.

4 Liden, S, et al, Acta Dermato-Venereologica, 1971, 51, 221.

${ }^{5}$ Kohn, K W, Analytical Chemistry, 1961, 33, 862.
}

\section{Serum levels of doxycycline in normal subjects after a single oral dose}

Doxycycline (Vibramycin) gives prolonged and therapeutic serum levels after single oral doses of 100,150 , and $250 \mathrm{mg}$ per day. This, compared with other tetracyclines, makes a once a day treatment schedule possible and rational. ${ }^{1}$ Single-dose therapy at $100 \mathrm{mg}$ and
Metabolic Research Unit, Department of Chemical Pathology, University of Ibadan, Ibadan, Nigeria

B KWAKU ADADEVOH, MD, FRCP, professor J O BOLODEOKU, MD, lecturer
I A OGUNNAIKE, FIMLT, technologist

Mean serum concentrations of doxycycline ( $\pm S E$ of mean)

\begin{tabular}{|c|c|c|c|c|c|c|c|c|c|c|c|}
\hline & Hours: & 0 & 1 & 2 & 4 & 6 & 24 & 48 & 72 & 96 & 120 \\
\hline $\begin{array}{l}\text { sean (mg/l) } \\
\text { SE of mean } \\
\text { No of subjects }\end{array}$ & $\begin{array}{ll} & \\
\therefore & \end{array}$ & $\begin{array}{c}0.50 \\
0.10 \\
20\end{array}$ & $\begin{array}{c}7.03 \\
0.65 \\
20\end{array}$ & $\begin{array}{c}11 \cdot 15 \\
0.57 \\
20\end{array}$ & $\begin{array}{c}15 \cdot 29 \\
0.80 \\
11\end{array}$ & $\begin{array}{c}10.86 \\
1.65 \\
9\end{array}$ & $\begin{array}{c}6.60 \\
0.66 \\
20\end{array}$ & $\begin{array}{c}3.42 \\
0.62 \\
20\end{array}$ & $\begin{array}{c}1 \cdot 24 \\
0 \cdot 17 \\
9\end{array}$ & $\begin{array}{c}1.00 \\
0.04 \\
9\end{array}$ & $\begin{array}{r}0.40 \\
0.07 \\
9\end{array}$ \\
\hline
\end{tabular}

At 144 hours in three subjects levels were $0.40,0.20$, and $0.20 \mathrm{mg} / 1$. 